University of South Carolina

Scholar Commons

7-1-2005

\title{
Mechanics of Hydrogenated Amorphous Carbon Deposits from Electron-Beam-Induced Deposition of Paraffin Precursor
}

W. Ding

D. A. Dikin

X. Chen

R. D. Piner

R. S. Ruoff

See next page for additional authors

Follow this and additional works at: https://scholarcommons.sc.edu/emec_facpub

Part of the Applied Mechanics Commons, and the Electro-Mechanical Systems Commons

Publication Info

Published in Journal of Applied Physics, Volume 98, Issue 1, 2005, pages \#014905-.

(C) Journal of Applied Physics 2005, American Institute of Physics.

Ding, W., Dikin, D. A., Chen, X., Piner, R. D., Fuogg, R. S., Zussman, E., Wang, X., \& Li, X. (1 July 2005).

Mechanics of Hydrogenated Amorphous Carbon Deposits from Electron-Beam-Induced Deposition of

Paraffin Precursor. Journal of Applied Physics, 98 (1), \#014905. http://dx.doi.org/10.1063/1.1940138

This Article is brought to you by the Mechanical Engineering, Department of at Scholar Commons. It has been accepted for inclusion in Faculty Publications by an authorized administrator of Scholar Commons. For more information, please contact digres@mailbox.sc.edu. 


\section{Author(s)}

W. Ding, D. A. Dikin, X. Chen, R. D. Piner, R. S. Ruoff, E. Zussman, X. Wang, and Xiaodong Li 


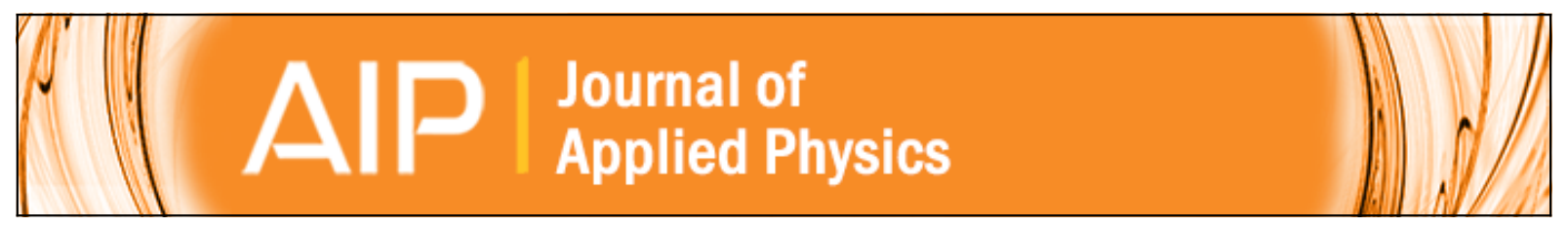

\section{Mechanics of hydrogenated amorphous carbon deposits from electron-beam-induced deposition of a paraffin precursor}

W. Ding, D. A. Dikin, X. Chen, R. D. Piner, R. S. Ruoff, E. Zussman, X. Wang, and X. Li

Citation: Journal of Applied Physics 98, 014905 (2005); doi: 10.1063/1.1940138

View online: http://dx.doi.org/10.1063/1.1940138

View Table of Contents: http://scitation.aip.org/content/aip/journal/jap/98/1?ver=pdfcov

Published by the AIP Publishing

\section{Articles you may be interested in}

s p 3 -rich deposition conditions and growth mechanism of tetrahedral amorphous carbon films deposited using filtered arc

J. Appl. Phys. 104, 013512 (2008); 10.1063/1.2951588

Deposition and patterning of diamondlike carbon as antiwear nanoimprint templates

J. Vac. Sci. Technol. B 24, 2993 (2006); 10.1116/1.2363409

Effects of thermal annealing on the structural, mechanical, and tribological properties of hard fluorinated carbon films deposited by plasma enhanced chemical vapor deposition

J. Vac. Sci. Technol. A 22, 2321 (2004); 10.1116/1.1795833

Microstructure and mechanical properties of nanocomposite amorphous carbon films

J. Vac. Sci. Technol. A 20, 1390 (2002); 10.1116/1.1486227

Effect of chamber pressure and atmosphere on the microstructure and nanomechanical properties of amorphous carbon films prepared by pulsed laser deposition

J. Vac. Sci. Technol. A 19, 311 (2001); 10.1116/1.1322641
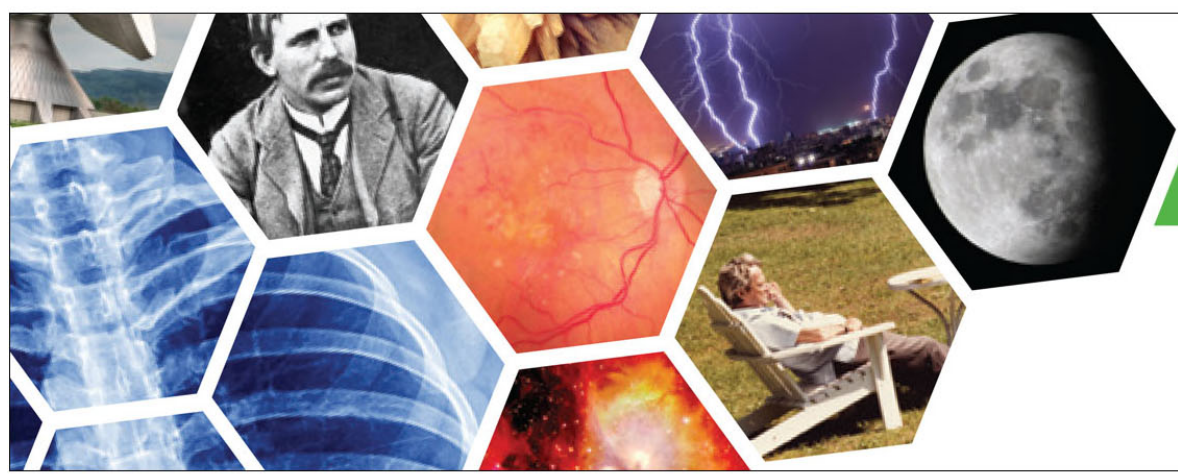

\section{SUBSCRIBE TO \\ physics today}




\title{
Mechanics of hydrogenated amorphous carbon deposits from electron-beam-induced deposition of a paraffin precursor
}

\author{
W. Ding, D. A. Dikin, X. Chen, R. D. Piner, R. S. Ruoff, ${ }^{\text {a) }}$ and E. Zussman ${ }^{\text {b) }}$ \\ Department of Mechanical Engineering, Northwestern University, Evanston, Illinois 60208 \\ X. Wang and X. Li \\ Department of Mechanical Engineering, University of South Carolina, Columbia, South Carolina 29208
}

(Received 6 October 2004; accepted 1 May 2005; published online 7 July 2005)

\begin{abstract}
Many experiments on the mechanics of nanostructures require the creation of rigid clamps at specific locations. In this work, electron-beam-induced deposition (EBID) has been used to deposit carbon films that are similar to those that have recently been used for clamping nanostructures. The film deposition rate was accelerated by placing a paraffin source of hydrocarbon near the area where the EBID deposits were made. High-resolution transmission electron microscopy, electron-energy-loss spectroscopy, Raman spectroscopy, secondary-ion-mass spectrometry, and nanoindentation were used to characterize the chemical composition and the mechanics of the carbonaceous deposits. The typical EBID deposit was found to be hydrogenated amorphous carbon $(a-\mathrm{C}: \mathrm{H})$ having more $s p^{2}$ - than $s p^{3}$-bonded carbon. Nanoindentation tests revealed a hardness of $\sim 4 \mathrm{GPa}$ and an elastic modulus of 30-60 GPa, depending on the accelerating voltage. This reflects a relatively soft film, which is built out of precursor molecular ions impacting the growing surface layer with low energies. The use of such deposits as clamps for tensile tests of poly(acrylonitrile)-based carbon nanofibers loaded between opposing atomic force microscope cantilevers is presented as an example application (C) 2005 American Institute of Physics.
\end{abstract}

[DOI: $10.1063 / 1.1940138$ ]

\section{INTRODUCTION}

One of the challenges in characterizing the mechanical properties of a specimen is the formation of appropriate clamps. This is particularly true and hard to accomplish for nanoscale specimens. In this work we demonstrate clamping of nanofibers, having diameters of 50-300 nm, based on electron-beam-induced deposition (EBID) and report on the structural and mechanical properties of these clamps.

A common clamping approach employs the high surface energy of nanostructures. Cuenot et al. ${ }^{1}$ and Salvetat et al. ${ }^{2}$ used this method in three-point bending tests of carbon nanotubes (CNT's) with an atomic force microscope (AFM). This approach depends strongly on the ambient humidity, surface flatness, and cleanness, and can be reliably used for nanostructures having a thickness or diameter below about $50 \mathrm{~nm}$. Another approach by Dai et ll $^{3}$ involved attaching CNT's to an atomic force microscope tip with an adhesive. Controlling the CNT orientation is very difficult by this method, and the viscosity of the adhesive could lead to undesirable wetting (coating) of many nanoscale specimens. Another method that has been used for clamping is based on EBID. The EBID process uses a high-intensity electron beam in an electron microscope to induce the formation of deposited structures on the scanned surfaces. It has been used to attach CNT's to AFM cantilever tips (Ref. 4) and onto microelectrodes. ${ }^{5}$ The EBID process creates a deposit that coats a small region of

\footnotetext{
${ }^{a)}$ Electronic mail: r-ruoff@northwestern.edu

${ }^{b)}$ Permanent address: Department of Mechanical Engineering, Technion Israel Institute of Technology, Haifa 32000, Israel; electronic mail: meeyal@tx.technion.ac.il
}

CNT. It allows control of orientation of the clamped nanostructures and is not constrained to a specific surface texture.

EBID is commonly observed during electron microscope observation. One of the earliest observations was reported by Watson in 1947 who found that carbon black particles appeared to increase in size during electron microscope examination. ${ }^{6}$ Similar observations were reported by other researchers, and the sources of specimen contamination were investigated. $^{7-12}$ The contamination was believed to be the result of interaction between the electron beam and organic molecules adsorbed on the bombarded surface. Several models were proposed for the arrival of hydrocarbon molecules at the irradiated region. Ennos believed that most of the molecules arrive onto the surface directly from the vapor and not by migration. ${ }^{9}$ Later Hart et al. showed that the surface migration of adsorbed gas to the irradiated area is an important contributor to deposited carbon. ${ }^{12}$ Early research work on EBID focused on reducing its effect in contaminating the surface of the samples during electron microscopy studies. Later, EBID was used to produce electrically insulating thin films when silicone oil vapor was deliberately introduced, ${ }^{13}$ to repair photomasks, ${ }^{14}$ to fabricate conductive lines, ${ }^{15,16}$ and to construct three-dimensional nanoscale structures. ${ }^{16,17}$ EBID is used in our work on the mechanics of nanostructures to fabricate clamps in the scanning electron microscope (SEM). ${ }^{4,18-20}$

EBID has typically been done inside a scanning electron microscope with a gas delivery system that provides the precursor molecules. ${ }^{14,16,21}$ In this case, the precursor material is heated in a reservoir and delivered as a vapor to the substrate through a tube. A manipulator can be used to position the tip 


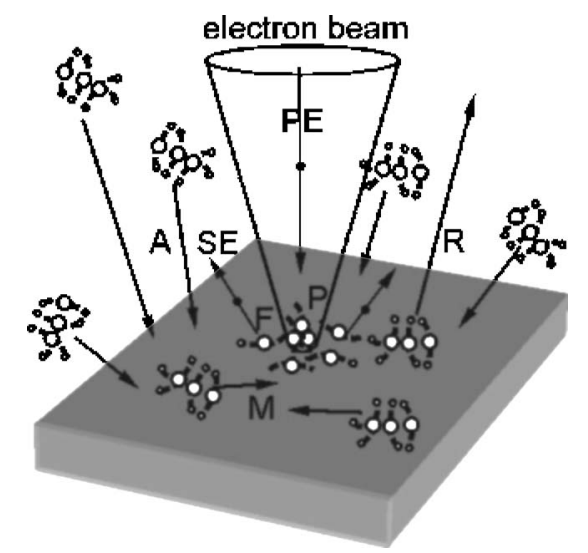

FIG. 1. A general view of the EBID process: primary electron (PE) and secondary electron (SE), precursor molecules adsorbed $\mathbf{A}$, reevaporated $\mathbf{R}$, migrated $\mathbf{M}$, fragmented $\mathbf{F}$, and polymerized $\mathbf{P}$.

of the tube close to the deposition area. In some applications an environmental SEM (Ref. 22) or a specially designed environmental subchamber inside of high-vacuum SEM (Ref. 23) has also been used. EBID is also commonly done inside SEM's with the residual hydrocarbon containments ${ }^{24}$ that are always present at standard operating pressures of $10^{-6}-10^{-7}$ Torr. However, the mechanism of clamp formation by EBID and its structural and mechanical properties have not been investigated in great detail.

The goal of this work was to develop a technique for rapid and robust EBID clamping and to characterize the composition, atomic structure, and mechanical properties of the clamp. We have chosen to make EBID deposits from a flux of hydrocarbon molecules emanating out of a paraffin source sitting close to the clamp formation region, thus providing control of the precursor type and increasing the deposition rate. We discuss first the EBID mechanism and then the experimental results of EBID arising from a well-defined hydrocarbon source. Our efficient approach for rapid clamping of nanostructures is presented with an example of tensile test experiments of poly(acrylonitrile) (PAN)-based carbon nanofibers.

\section{THE EBID MECHANISM}

EBID is the process of using a high-intensity electron beam, usually within a SEM, to deposit structures on a scanned surface. ${ }^{9,11,12,23,25}$ The principle of the EBID process is shown in Fig. 1. The primary electron beam is focused on a substrate surface that is coated with adsorbed precursor molecules. The rate at which molecules arrive at the position of the electron beam is limited by two factors. One is the rate at which molecules adsorb onto the substrate. The second is the rate at which molecules diffuse across the surface until they are under the electron beam. ${ }^{26,27}$ When primary electrons strike the surface they are scattered either elastically (backscattered) or inelastically inside the substrate. Both create secondary electrons that are emitted backward into the vacuum chamber. The emission rate of the secondary (inelastic scattered) and backscattered (elastic scattered) electrons depends not only on the kinetic energy of the primary electrons, but also on the incident angles with respect to the irradiated surfaces, and the material properties. The secondary electrons have main energy spread from 0 up to $\sim 50 \mathrm{eV}$. These lower-energy electrons have nearly optimal cross section for fragmenting hydrocarbon molecules through electron-molecule collisions, ${ }^{27,28}$ which disassociate adsorbed molecules. The cross section for the creation of reactive species from the gas phase precursors is quite small. The secondary and backscattered electrons are emitted from a substrate through a slightly larger area than the primary irradiation and thus lead to an increase in the EBID deposit size beyond the beam waist size. ${ }^{14,16,29-32}$

The deposition rate depends on the primary electronbeam flux and energy, on the adsorption rate of the precursor gas molecules onto the substrate and their surface mobility, on the flux of vapor phase molecules from the precursor source, and on the probability for the primary and secondary electrons to create molecular fragments that can be polymerized on the irradiated surface. ${ }^{25}$

\section{EXPERIMENT}

\section{A. Material}

As a precursor source we used $n$-docosane $\left(\mathrm{C}_{22} \mathrm{H}_{46}\right.$; Alfa Aesar) and perdeuterated $n$-tetracosane $\left(\mathrm{C}_{24} \mathrm{H}_{50}\right.$; Cambridge Isotope Laboratory); each is a solid and has a vapor pressure less than $10^{-3}$ Torr at room temperature. ${ }^{33}$ The paraffin was dissolved in toluene to make a $3 \mathrm{wt} \%$ solution. A small drop $(\sim 0.1 \mathrm{ml})$ of the solution was dropped on a single-crystal silicon (100) substrate (2-10 $\Omega \mathrm{cm}, p$-type, polished, Polishing Corporation of America) previously cleaned with oxygen plasma (Plasmatic Systems Inc., II-862). After the toluene/ paraffin solution evaporated, a film visible by light microscope containing the paraffin was left on the substrate. In addition, a sharp glass pipet was used to pick up a small drop of the paraffin solution, and after the solvent evaporated, the tip of the pipet was covered with a thin paraffin film. Under an inverted light microscope (Zeiss Axiovert 100A, Carl Zeiss, Jena, Germany) with two micropositioning stages, AFM tips (MikroMasch, type NSC12/3, platinum-coated silicon) were brought into contact with the paraffin film at the tip of the pipet, and a small amount of paraffin was transferred to the surfaces of the AFM tips. Later, nanostructures were clamped to these AFM tips at locations close to the paraffin source with the EBID method, and tensile loading experiments were performed.

\section{B. Deposition and characterization}

The EBID processes described in this paper were done inside a LEO 1525 field-emission gun (FEG) SEM, and performed at 3-, 12-, and $20-\mathrm{kV}$ accelerating voltages and $\sim 100$-pA electron-beam current. The SEM chamber was maintained at a pressure of $\sim 10^{-6}$ Torr during the experiments. To create a deposit, a region close to the paraffin precursor was scanned (raster mode) by the $e$ beam.

AFM images (Park Scientific model CP Research) of the EBID deposits were acquired. Contact mode images were obtained with Park Scientific microlevers with silicon nitride tips. Raman spectra of EBID material deposited on the silicon wafer were taken with a Renishaw Raman microspec- 
trometer (514.5-nm excitation, $\sim 15 \mathrm{~mW}$ power; $\sim 0.8-\mu \mathrm{m}$ diameter focus spot using $a \times 100$ microscope objective and notch filter between 500 and $4000 \mathrm{~cm}^{-1}$ ). Electron-energyloss spectrometry [EELS; Hitachi HF-2000 FEG transmission electron microscope (TEM)] was used to determine the $s p^{2} / s p^{3}$ ratio for the EBID deposits formed on 50-nm-thick $\mathrm{Si}_{3} \mathrm{~N}_{4}$ membranes (SPI Inc.); these thin films were deposited at accelerating voltages of 3,12, and $20 \mathrm{kV}$. EELS spectra were also obtained from two freely suspended EBID deposits made across holes on a lacey SiO TEM grid (Ted Pella, -300 mesh) at $3-\mathrm{kV}$ accelerating voltage. A graphite sample (HOPG; ZYB grade, SPI-2, SPI Inc.) was used as a reference for pure $s p^{2}$ bonding for EELS. Secondary-ion-mass spectrometry (SIMS; PHI TRIFT III, Physical Electronics) was used to identify the chemical element composition in the skin layer of $\sim 0.5$-nm depth with a high sensitivity ( $\sim 1 \mathrm{ppm})$. A Hysitron Troboscope nanoindenter with a Veeco Dimension 3100 AFM was used for nanoindentation tests. The nanoindenter monitors and records the load and displacement of a three-sided pyramidal diamond (Berkovich) indenter during indentation with a force resolution of $\sim 1 \mathrm{nN}$ and displacement resolution of $\sim 0.2 \mathrm{~nm}^{34,35}$ The indenter tip was used to image and locate the EBID deposit and then the deposit was indented in situ with the same tip. The indent was also imaged with the same tip. Hardness and elastic modulus were calculated from the load-displacement data obtained by nanoindentation.

\section{RESULTS AND DISCUSSION}

Figure 2 shows a rectangular-shaped EBID deposit $\left(\sim 9.5 \times 6.5 \mu \mathrm{m}^{2}\right)$ formed by a 50 -min exposure with a total area dose of $4.0 \mathrm{nC} / \mu \mathrm{m}^{2}$ at $3-\mathrm{kV}$ accelerating voltage; the paraffin source was located around $35 \mu \mathrm{m}$ away from the lower right side. The topological profile of the deposit measured by AFM is shown in Fig. 2(b). The height is uneven over the deposited area, and the region closer to the paraffin source is thicker than the rest of the deposit. As can be seen in Fig. 2(a), the sample edges are also much thicker than the rest of the deposit; this has been explained in terms of surface diffusion of unreacted adsorbed molecules at the perimeter of the deposit. ${ }^{27}$ Also, the four corners of the sample are higher than the edges, which is reasonable since the corners have a greater supply of unreacted molecules than the edges.

In another example, three arrays of posts were deposited $[A, B$, and $C$, Fig. 3(a)]. The paraffin source was located parallel to $A, B$, and $C$ and 10,15 , and $20 \mu \mathrm{m}$ away from these arrays, respectively. The deposition time for each post was increased along each array and was 2, 4, 6, 8, and 10 min, respectively. All the depositions were performed with an exposure area of $100 \times 100 \mathrm{~nm}$ resulting in a total area dose in the range of $1-6 \mu \mathrm{C} / \mu \mathrm{m}^{2}$ at $3-\mathrm{kV}$ accelerating voltage. Figure 3(b) shows the height of the posts as a function of the deposition time. It is clear that the initial deposition rate (from 0 to $2 \mathrm{~min}$ ) strongly depends on the distance from the paraffin source to the irradiated area; thus array $A$ is higher than $C$. Although we do not have experimental data in this time range, the estimated deposition rates are at least $1.25 \mu \mathrm{m} / \mathrm{min}$ for the closest array $(A)$ and $0.4 \mu \mathrm{m} / \mathrm{min}$ for
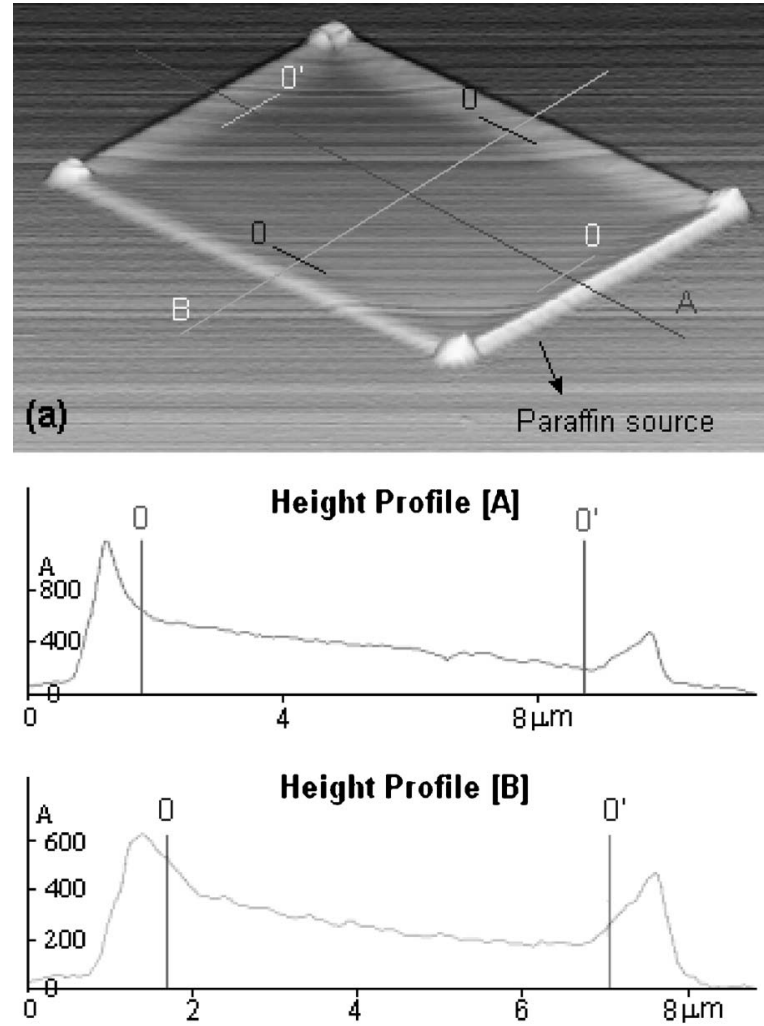

(b)

FIG. 2. (a) AFM image of a rectangular-shaped EBID deposition. The paraffin source is $\sim 35 \mu \mathrm{m}$ away (lower right, not on image). (b) Cross sections $\mathbf{A}$ and $\mathbf{B}$ of the EBID deposit.

the outermost one $(C)$, assuming growth is linear in time. The deposition rates measured in the time interval from 2 to $10 \mathrm{~min}$ are roughly the same for each array, which can be seen from the linear relationship between the post height and the time of exposure, and were $\sim 0.2 \mu \mathrm{m} / \mathrm{min}$. In the time range of $0-2$ mins the deposition is probably accelerated due to significant contribution of molecular surface diffusion from the unexposed (surrounding) area and secondary electron emission from the substrate. In the time range of $2-10$

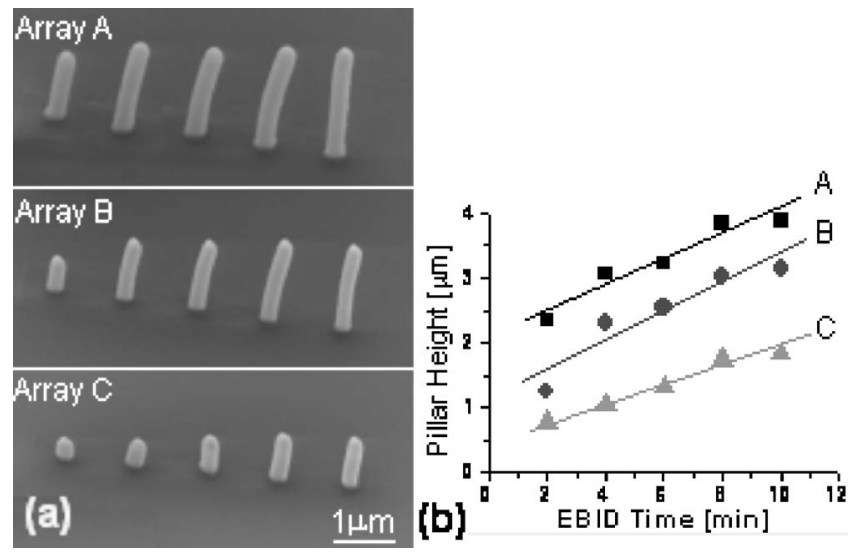

FIG. 3. (a) SEM images of five EBID-deposited posts in each array $A, B$ and $C$, located 10,15 , and $20 \mu \mathrm{m}$ from the paraffin source, respectively. The SEM images were acquired at $30^{\circ}$ tilt. The deposition time from left to right was $2,4,6,8$, and $10 \mathrm{~min}$, respectively. (b) Posts height vs deposition time and its linear fit. 


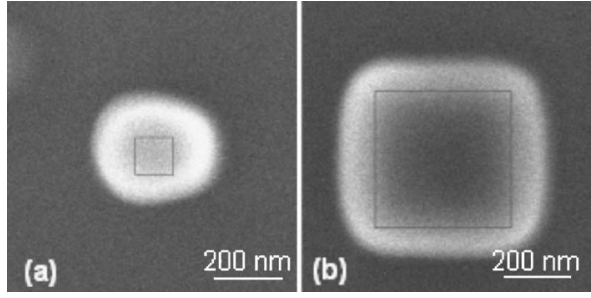

FIG. 4. SEM images of the EBID deposit size vs the exposure size (square area): (a) an exposure area of $100 \times 100 \mathrm{~nm}^{2}$ and (b) an exposure area of $400 \times 400 \mathrm{~nm}^{2}$.

mins the deposition rate drops most probably because the secondary electron emission is changed from the underlying deposit rather than from the substrate, and the molecular surface diffusion (mobility) along the carbonaceous deposit is also different than the substrate.

In contrast, when the EBID deposit is formed in the same SEM vacuum chamber but relying solely on residual hydrocarbon molecules naturally present in the system, the deposition rate is $\sim 0.005 \mu \mathrm{m} / \mathrm{min}$.

In another experiment a series of depositions was made with different exposure areas, varying from $100 \times 100$ to $400 \times 400 \mathrm{~nm}^{2}$ at $3-\mathrm{kV}$ accelerating voltage with the total dose of 18 and $1.44 \mu \mathrm{C} / \mu \mathrm{m}^{2}$, respectively. Imaging of the deposits showed that the structure formed always has a larger area than the nominally exposed area. This size increment along the perimeter is essentially the same, about $100 \mathrm{~nm}$, as can be seen in Fig. 4. Based on the model of Kanaya and Okayama, ${ }^{29}$ the expected additional increment of the secondary electrons (beyond the exposed area) for these experimental conditions is $113.3 \mathrm{~nm}$, which is in good agreement with the obtained results.

The EBID deposition rate depends on the energy of the primary electron beam, which is equal to the SEM accelerating voltage (expressed in eV). Figure 5 shows three posts made using the LEO 1525 SEM "spot mode" at 3-, 12-, and $20-\mathrm{kV}$ accelerating voltages, respectively (each with a 45-s exposure time; the paraffin source was located $\sim 3 \mu \mathrm{m}$ away in each case). The differences in height between the three posts indicate a smaller deposition rate with increasing accelerating voltage. It is known that low accelerating voltage favors a higher yield of secondary electrons ${ }^{30}$ that have a larger cross section for molecular decomposition ${ }^{27,28}$ and thus the EBID deposit growth. Note that the post diameters

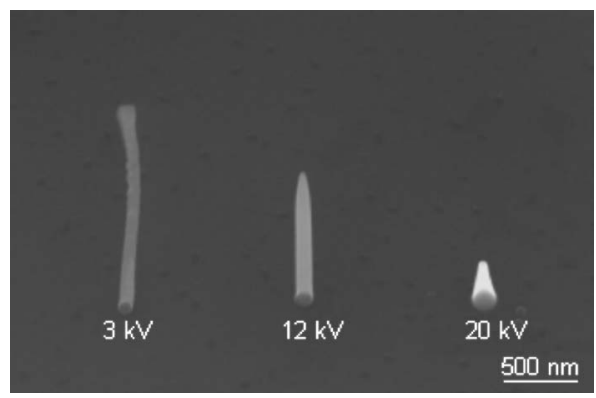

FIG. 5. SEM image of three posts fabricated with SEM "spot mode." The SEM image was acquired at $30^{\circ}$ tilt. The EBID deposition time was $45 \mathrm{~s}$ for all three posts and the paraffin source is located $\sim 3 \mu \mathrm{m}$ from each post.

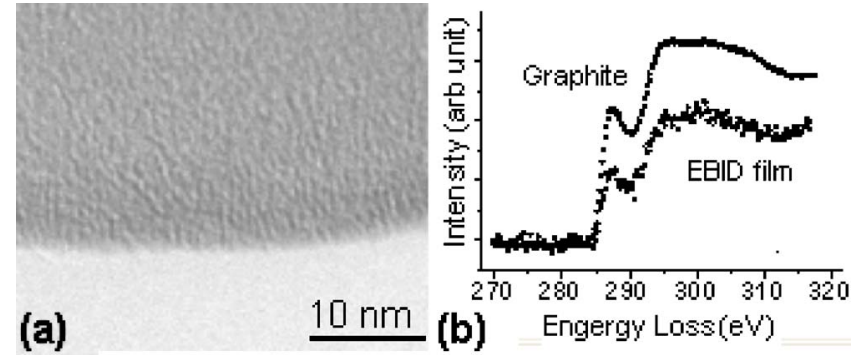

FIG. 6. (a) Bright-field TEM image of a freely suspended EBID structure. (b) EELS spectra of an EBID film deposited at 3-kV accelerating voltage on top of a 50-nm-thick $\mathrm{Si}_{3} \mathrm{~N}_{4}$ support film and of graphite (HOPG) used as a reference.

increase with larger accelerating voltage. Primary electrons with higher energy have larger penetration depth and thus larger backscatter range. ${ }^{14,16,29-32}$

The accelerating voltage clearly affects the deposition rate; it may also affect the film properties. To test this, thin films (in contrast with the posts mentioned above) were deposited onto thin silicon nitride support films (that were 50 $\mathrm{nm}$ thick), with the "line scan mode" of the LEO 1525 SEM, again with 3-, 12-, and 20-kV accelerating voltages.

EELS was used to characterize the structure of these deposited thin films. To determine the fraction of $s p^{2}$ and $s p^{3}$ carbon bonds, the three EELS spectra were analyzed by the method proposed by Cuomo et al. ${ }^{36}$ The fraction of the $s p^{2}$-bonded $\mathrm{C}$ (thus $s p^{2}$ bonds divided by the sum of $s p^{2}$ and $s p^{3}$ bonds) was found to be 0.92 (3-kV incident electrons), $0.87(12 \mathrm{kV})$, and $0.83(20 \mathrm{kV})$, respectively. In an earlier EBID deposition experiment with only $3-\mathrm{kV}$ incident electrons, for a free standing EBID structure that was deposited across the hole present in a lacey SiO TEM grid, the fraction of $s p^{2}$-bonded $\mathrm{C}$ was 0.70 . We feel that it is most useful to compare the values obtained on the samples made on the same (here, $\mathrm{Si}_{3} \mathrm{~N}_{4}$ ) substrate and during the same SEM session. It should be noted that EELS is typically thought to provide an accuracy of only roughly $\pm 10 \%$ for $s p^{2}$ and $s p^{3}$ content. Because the three EBID deposits are close together and EELS spectra were obtained with identical conditions, we quote two figures for the fit values. The reader should interpret these numbers as useful for comparing the relative $s p^{2}$ content between each deposit, rather than the $s p^{2}$ content being known to two significant figures. Figure 6(a) shows a bright-field TEM image of the EBID-deposited freely suspended structure. Figure 6(b) shows an EELS spectrum in the energy-loss range from 270 to $320 \mathrm{eV}$ acquired from one of the EBID-deposited films $(3 \mathrm{kV})$ on top of the thin $\mathrm{Si}_{3} \mathrm{~N}_{4}$ support film.

Figure 7 shows a typical Raman spectrum (1100-2000 $\mathrm{cm}^{-1}$ ) of an EBID film deposited at $3 \mathrm{kV}$ on a silicon substrate. There are two broad overlapping peaks centered around $1382.40 \mathrm{~cm}^{-1}$ (width $216.06 \mathrm{~cm}^{-1}$ ) and $1589.60 \mathrm{~cm}^{-1}$ (width $106.10 \mathrm{~cm}^{-1}$ ). These $D$ and $G$ peaks were fit using a Gaussian-Lorentzian mixed shape. ${ }^{37,38}$ The ratio of the integrated intensity of the $D$ and $G$ peaks, $I_{D} / I_{G}=0.67 \pm 0.04$, characterizes the disorder in the EBID film and is a measure of the number of disordered $(D)$ and ordered $(G) \mathrm{C}$ atoms. ${ }^{37}$ To first order, $I_{D}$ and $I_{G}$ share the 


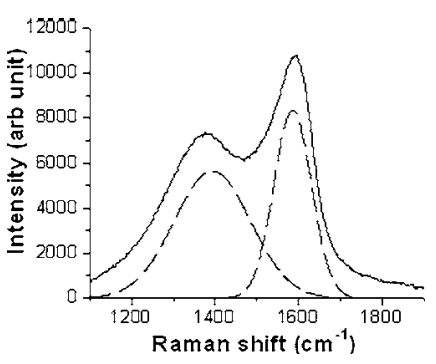

FIG. 7. A typical Raman spectrum of an EBID film (The dashed lines are the single fitted Gaussian-Lorentzian peaks).

same proportionality constant to the number of scattering centers; thus the ratio $I_{D} / I_{G}$ is $x_{D} / x_{G}$, where $x$ is the mole fraction. Solving $x_{G}=I_{G} /\left(I_{G}+I_{D}\right)=0.59 \pm 0.02$. Obtaining $s p^{3}$ content from 514.5-nm excitation Raman spectra depends on the linkage of $s p^{2}$ and $s p^{3}$ phases. Since hydrogen was observed in the EBID film it is known that the $C-C$ network is affected. ${ }^{37}$ A higher $s p^{3}$ content is achieved mainly by saturating $C=C$ bonds. The ratio $I_{G} /\left(I_{G}+I_{D}\right)$ $=0.59 \pm 0.02$ is a rough measure of the fraction of $s p^{2}$-bonded carbons.

In an attempt to identify the elemental composition of the EBID deposits, SIMS was used. Since it was nontrivial to distinguish $\mathrm{H}$ in the sample from the background $\mathrm{H}$, we used a deuterated paraffin (tetracosane, $\mathrm{C}_{24} \mathrm{D}_{50}$; Cambridge Isotopes Laboratories), which was the closest $n$-alkane in molecular size to $n$-docosane among the commercially available perdeuterated $n$-alkanes. We attempted to assign the most prominent SIMS peaks based on the Physical Electronics database. Carbon and deuterium ions from the EBID film were readily detected (Fig. 8). Hydrogen-ion traces were also detected, but were distributed across the whole substrate. However, the counts from the EBID area were higher than from the immediate surroundings. Apparently, besides surface contamination, the EBID structure has some simultaneously deposited hydrogen from the residual molecules always present in the SEM chamber used.

Taking into account the EELS, TEM image data, Raman, and SIMS, the EBID film is amorphous, has more $\mathrm{sp}^{2}$ - than $\mathrm{sp}^{3}$-bonded $\mathrm{C}$, and contains some $\mathrm{H}$.

A Berkovich diamond nanoindenter tip was used to locate and image an EBID deposit and thus to position the indenter tip on the film to perform an indentation test. AFM images are shown in Fig. 9, as an example; this EBID deposit is a $\sim 15 \times 15 \mu \mathrm{m}^{2}$ area with a height of about $250 \mathrm{~nm}$ at the center and was deposited at $3-\mathrm{kV}$ accelerating voltage. The film edge is thicker than the central region. An array of

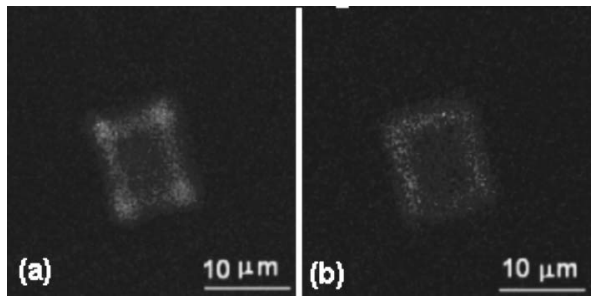

FIG. 8. SIMS elemental maps of the rectangular EBID film (nominally) from $\mathrm{C}_{24} \mathrm{D}_{50}$. The respective maps are (a) carbon and (b) deuterium.
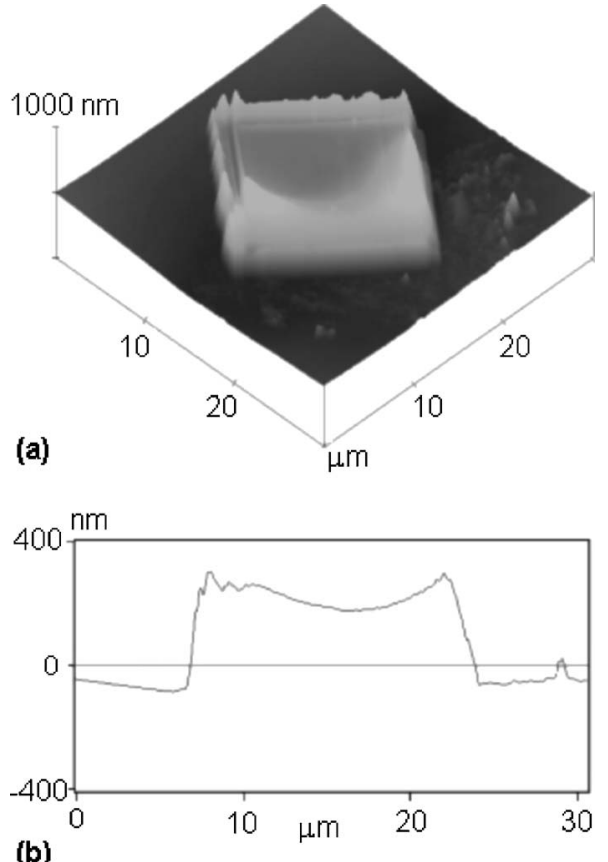

FIG. 9. (a) AFM image of the tested EBID sample before nanoindentation tests. (b) A line scan of the sample.

nanoscale indentations at different indentation loads was made on this deposit. Figure 10 shows the load-displacement curves of indentations made at a $150-\mu \mathrm{N}$ peak indentation load, the calculated hardness and elastic modulus of this film deposited at $3 \mathrm{kV}$, and also two additional films deposited at $12-$ and $20-\mathrm{kV}$ accelerating voltages, respectively. For all the deposited films, a distinct characteristic was the high elastic recovery after being subjected to a peak indentation load (note, however, that the recovery is not complete, see Fig. 11). The inelastic/plastic deformation depths (residual depths) for the films deposited at 3,12 , and $20 \mathrm{kV}$ obtained
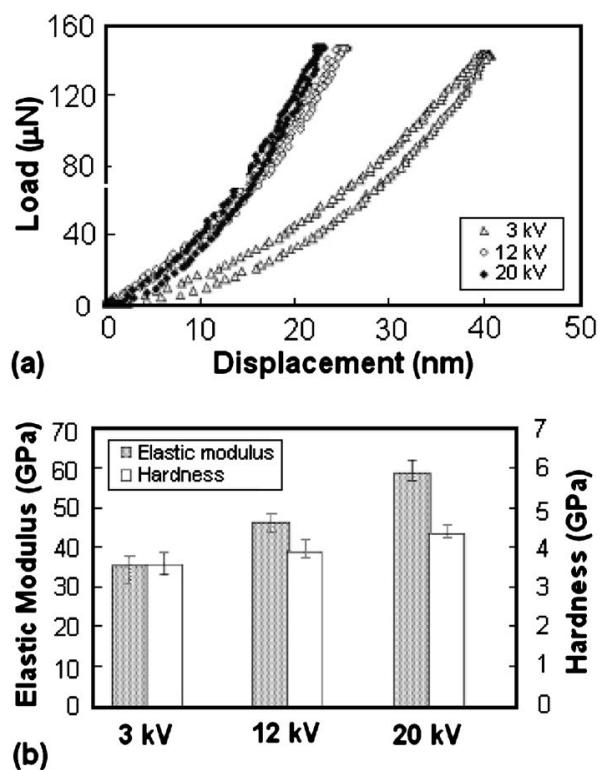

FIG. 10. (a) Representative load-displacement curves of indentations made at $150-\mu \mathrm{N}$ peak indentation load for EBID films made at 3-, 12-, and 20-kV accelerating voltages, respectively. (b) The hardness and elastic modulus results. 

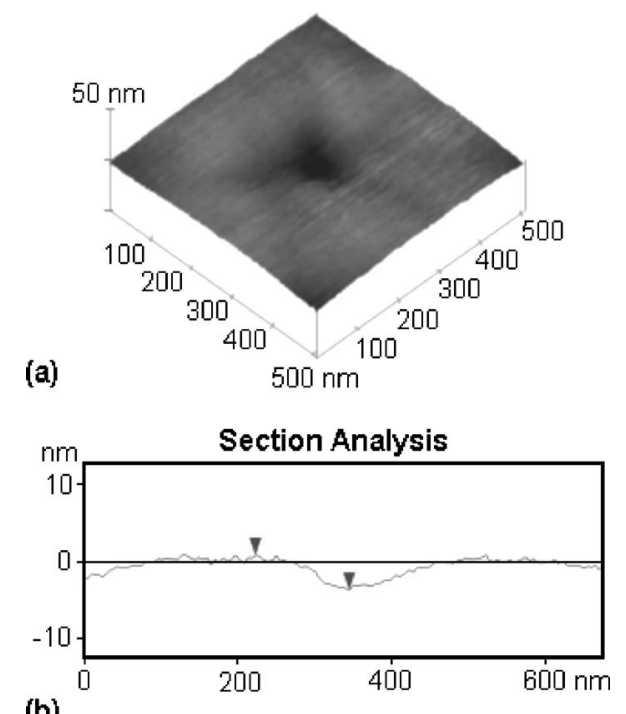

(b)

FIG. 11. (a) AFM image and (b) a line scan of the residual indentation impression made at a peak indentation load of $150 \mu \mathrm{N}$.

from the nanoindentation unloading curves [Fig. 10(a)] are 2.3, 1.8 , and $1.7 \mathrm{~nm}$, respectively. The peak nanoindentation depths are 40, 25, and $23 \mathrm{~nm}$ for the films deposited at 3, 12, and $20 \mathrm{kV}$ [Fig. 10(a)], which are less than $15 \%$ of the film thickness in each case. Therefore, the substrate effect on the measurements of hardness and elastic modulus is negligible. ${ }^{34,35}$ The indentation impressions (see Fig. 11) were imaged immediately after the indentation tests using the same tip, verifying that the test was performed in the anticipated location. The projected areas obtained by the AFM from the indentation were used to calibrate the hardness and elastic modulus values. Poisson's ratio for hydrogenated amorphous carbon films was measured to be $0.25 \pm 0.05$ by Marques et al. ${ }^{39}$ and this Poisson's ratio value was used to calculate the elastic modulus using the obtained nanoindentation load-displacement data. With the indentation projected area calibration, the hardness and elastic modulus values of the films deposited under 3,12 , and $20 \mathrm{kV}$ were fitted as $3.6 \pm 0.3,4.0 \pm 0.2$, and $4.4 \pm 0.2 \mathrm{GPa}$, and $34.3 \pm 3.4,46.3 \pm 2.3$, and $59.5 \pm 2.5 \mathrm{GPa}$, respectively.

These elastic modulus values are in good agreement with the values obtained from hydrogenated amorphous carbon films with $s p^{2}$-bonded carbon fraction of $\sim 0.65$, by Marques et $a .^{39}$ The low measured hardness of each EBID film is consistent with $a$-C:H films deposited from hydrocarbon plasma at low bias voltage $(200 \mathrm{~V} ; \mathrm{H}<5 \mathrm{GPa}){ }^{40,41}$ It is well known that the mechanical properties of plasma-deposited $a$-C:H depend mainly on the energy with which the hydrocarbon precursors impact the growing surface and the amount of hydrogen in the film. ${ }^{41}$

The measured elastic modulus of $30-60 \mathrm{GPa}$ is substantially lower than the lowest value $(\sim 100 \mathrm{GPa})$ for $a-\mathrm{C}: \mathrm{H}$ as modeled by Tersoff. ${ }^{42}$ However, this computed minimum value assumed a hydrogenated amorphous carbon with nearly ideal $s p^{3}$ bonding. Our data suggests that this is not the case for the EBID deposits characterized here. Although there is an increase in both hardness and elastic modulus of the EBID deposits, if one considers that Young's modulus of

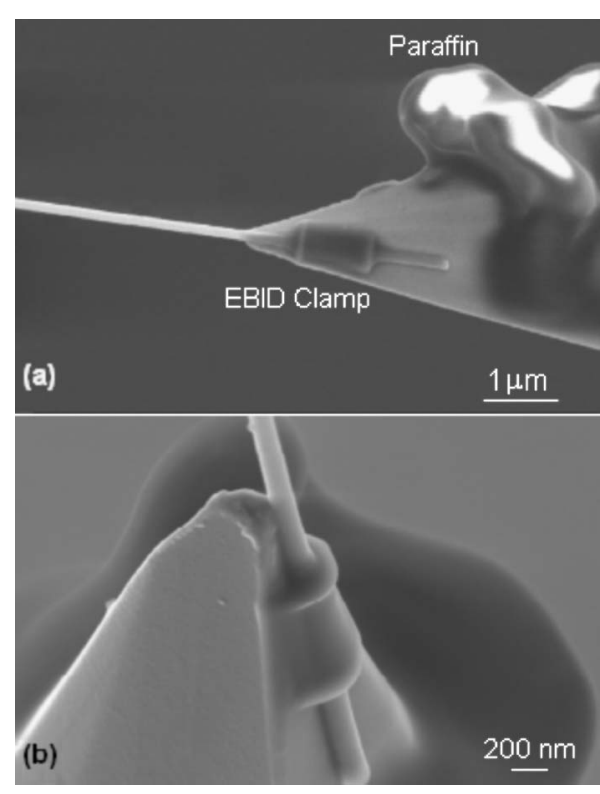

FIG. 12. SEM image of a carbonized PAN fiber clamped to an AFM cantilever tip with EBID method: (a) side view and (b) top view at $30^{\circ}$ tilt.

polycrystalline diamond is $1043 \mathrm{GPa},{ }^{43}$ the increases obtained here with increasing accelerating voltage (resulting from increasing $s p^{3}$ content for these $s p^{2}$-rich $a-\mathrm{C}: \mathrm{H}$ deposits) are modest. The hardness/elastic ratio $H / E \approx 0.1$ is consistent with the state-of-the-art results on other $a-\mathrm{C}: \mathrm{H}$ films. ${ }^{44}$ Amorphous hydrogenated carbon films consist of a mixture of $s p^{2}$ - and $s p^{3}$-bonded $\mathrm{C}$ atoms, and $\mathrm{H}$. When the $s p^{2}$ content is high, as is the case for the EBID-deposited films studied here, one expects lower elastic modulus and hardness. High hydrogen content in the EBID-deposited film, if present, would introduce frequent terminations in what would otherwise be a strong three-dimensional network and thereby increase the soft polymeric component of the structure. ${ }^{45}$

In order to test the utility of EBID for making clamps for small specimens, we clamped several carbon fibers and performed tensile loading experiments based on the technique described in Ref. 46. The fibers were electropsun from PAN and further carbonized, their average diameter was $150 \mathrm{~nm}$. For such a diameter, a thick and relatively long deposit was needed to ensure that the clamp would not fail during the tensile loading. Based on the above experimental data, if the goal is to control the deposit size one would use the lower accelerating voltage, due to the back scatter effect mentioned above.

Our use of a solid hydrocarbon (paraffin) located close to the fiber clamping position $(<10 \mu \mathrm{m})$ accelerated clamp production dramatically, which is important for rapid configuration of the mechanics experiment. Figure 12 shows the EBID clamp holding a carbonized PAN fiber (diameter of $140 \pm 5 \mathrm{~nm}$ ) on the AFM tip. The clamp area produced for these tests was typically $\sim 500 \times 500 \mathrm{~nm}^{2}$, around $100 \mathrm{~nm}$ thick, and was created in less than 15 mins. The maximum force that this clamp withstood during tensile tests was about $100 \mu \mathrm{N}$ with $\sim 30 \mathrm{MPa}$ of average interfacial shear stress at the carbon fiber/EBID clamp interface. In all cases, failure occurred not at the clamp, but in the fiber. 


\section{CONCLUSIONS}

A rapid method for the clamp formation of nanostructures using EBID in a SEM was presented. By deliberately providing a source of hydrocarbon (paraffin) near the region where the EBID deposit has to be made, the deposition rate can be increased tens of times compared to a typical deposition from the residual hydrocarbons inside a SEM. The increased rate of the deposition depends on the distance from the paraffin source and also on the volume of the EBID deposit. Surface diffusion of the precursor material is responsible for the faster growing process on the perimeter of the deposited structures. The deposit area was always larger than the (nominal) scanned area. Analysis by EELS, TEM, Raman, SIMS, and nanoindentation shows that the EBID deposits are hydrogenated amorphous carbon $(a-\mathrm{C}: \mathrm{H})$ with more $s p^{2}$ - than $s p^{3}$-bonded carbon. The influence of SEM accelerating voltage on the deposition rate and material properties was investigated. Higher accelerating voltage led to lower deposition rate but slightly higher $s p^{3}$ fraction. Nanoindentation tests revealed a slight increase in hardness and elastic modulus for the higher accelerating voltages.

This method of creating a deposit was used to rapidly form clamps for tensile loading of carbonized PAN fibers. ${ }^{46}$ Further research is underway for more versatile delivery of various precursors for the formation of clamps for mechanical measurements on small structures.

\section{ACKNOWLEDGMENTS}

This work was funded by the Office of Naval Research under Grant No. N000140210870. One of the authers (E.Z.) was supported by the National Science Foundation under Grant No. 0200797 (Ken Chong, Program Director). Two of the authors (D.D. and X.C.) were supported in part by the National Science Foundation (NIRT program, Grant No. 0304506, Dr. Ken P. Chong, Program Director) and by the NASA University Research, Engineering and Technology Institute on Bio Inspired Materials (BIMat) under Award No. NCC-1-02037. Coauthors X.W. and X.L. were supported by the National Science Foundation (Grant No. EPS-0296165), the South Carolina Space Grant Consortium-NASA, and the University of South Carolina NanoCenter Seed Grant. We are grateful to the NUANCE facility at Northwestern University for SEM and TEM experiments.

${ }^{1}$ S. Cuenot, S. Demoustier-Champagne, and B. Nysten, Phys. Rev. Lett. 85, 1690 (2000).

${ }^{2}$ J. P. Salvetat, J. M. Bonard, N. H. Thomson, A. J. Kulik, L. Forro, W. Benoit, and L. Zuppiroli, Appl. Phys. A: Mater. Sci. Process. 69, 255 (1999).

${ }^{3}$ H. J. Dai, J. H. Hafner, A. G. Rinzler, D. T. Colbert, and R. E. Smalley, Nature (London) 384, 147 (1996).

${ }^{4}$ M. F. Yu, O. Lourie, M. J. Dyer, K. Moloni, T. F. Kelly, and R. S. Ruoff, Science 287, 637 (2000)

${ }^{5}$ D. N. Madsen, K. Molhave, R. Mateiu, A. M. Rasmussen, M. Brorson, C.
J. H. Jacobsen, and P. Boggild, Nano Lett. 3, 47 (2003).

${ }^{6}$ J. H. L. Watson, J. Appl. Phys. 18, 153 (1947).

${ }^{7}$ V. E. Cosslett, J. Appl. Phys. 18, 844 (1947).

${ }^{8}$ J. Hillier, J. Appl. Phys. 19, 226 (1948).

${ }^{9}$ A. E. Ennos, Br. J. Appl. Phys. 4, 101 (1953).

${ }^{10}$ K. M. Poole, Proc. Phys. Soc. London, Sect. B 66, 542 (1953).

${ }^{11}$ A. E. Ennos, Br. J. Appl. Phys. 5, 27 (1954).

${ }^{12}$ R. K. Hart, T. F. Kassner, and J. K. Maurin, Philos. Mag. 21, 453 (1970).

${ }^{13}$ R. W. Christy, J. Appl. Phys. 311680 (1960).

${ }^{14}$ H. W. P. Koops, R. Weiel, D. P. Kern, and T. H. Baum, J. Vac. Sci. Technol. B 6, 477 (1988).

${ }^{15}$ H. Hiroshima, N. Suzuki, N. Ogawa, and M. Komuro, Jpn. J. Appl. Phys., Part 1 38, 7135 (1999).

${ }^{16}$ Y. M. Lau, P. C. Chee, J. T. L. Thong, and V. Ng, J. Vac. Sci. Technol. A 20, 1295 (2002)

${ }^{17}$ H. W. P. Koops, J. Kretz, M. Rudolph, and M. Weber, J. Vac. Sci. Technol. B 11, 2386 (1993)

${ }^{18}$ D. A. Dikin, X. Chen, W. Ding, G. Wagner, and R. S. Ruoff, J. Appl. Phys. 93, 226 (2003).

${ }^{19}$ X. Chen, S. Zhang, D. A. Dikin, W. Ding, R. S. Ruoff, L. Pan, and Y. Nakayama, Nano Lett. 3, 1299 (2003).

${ }^{20} \mathrm{~W}$. Ding et al., Nano Lett. 3, 1593 (2003).

${ }^{21}$ H. Hiroshima and M. Komuro, Jpn. J. Appl. Phys., Part 1 36, 7686 (1997).

${ }^{22}$ Y. Akama, E. Nishimura, A. Sakai, and H. Murakami, J. Vac. Sci. Technol. A 8, 429 (1990).

${ }^{23}$ M. Weber, H. W. P. Koops, M. Rudolph, J. Kretz, and G. Schmidt, J. Vac. Sci. Technol. B 13, 1364 (1995).

${ }^{24}$ A. Avramescu, A. Ueta, K. Uesugi, and I. Suemune, Appl. Phys. Lett. 72, 716 (1998).

${ }^{25}$ J. J. Hren, in Principles of Analytical Electron Microscopy, edited by D. C. Joy, A. D. J. Romig, and J. I. Goldstein (Plenum, New York, 1986), Chap. 10.

${ }^{26}$ N. Silvis-Cividjian, C. W. Hagen, P. Kruit, M. A. J. Van der Stam, and H. B. Groen, Appl. Phys. Lett. 82, 3514 (2003).

${ }^{27}$ M. Amman, J. W. Sleight, D. R. Lombardi, R. E. Welser, M. R. Deshpande, M. A. Reed, and L. J. Guido, J. Vac. Sci. Technol. B 14, 54 (1996).

${ }^{28}$ L. Sanche, IEEE Trans. Dielectr. Electr. Insul. 4, 507 (1997).

${ }^{29}$ K. Kanaya and S. Okayama, J. Phys. D 5, 43 (1972).

${ }^{30}$ L. Reimer, Scanning Electron Microscopy: Physics of Image Formation and Microanalysis (Springer, New York, 1985).

${ }^{31}$ K. Mitsuishi, Z. Q. Liu, M. Shimojo, M. Han, and K. Furuya, Ultramicroscopy 103, 17 (2005).

${ }^{32}$ N. Silvis-Cividjian, C. W. Hagen, L. H. A. Leunissen, and P. Kruit, Microelectron. Eng. 61-2, 693 (2002).

${ }^{33} \mathrm{http} / / / \mathrm{www}$. cheric.org/kdb/ with the assumption that extrapolation of the Antoine equation is valid, the vapor pressure at $298 \mathrm{~K}$ is $2 \times 10^{-5}$ Torr for $n$-docosane and $4 \times 10^{-8}$ Torr for $n$-Tetracosane.

${ }^{34} \mathrm{~B}$. Bhushan and X. Li, Int. Mater. Rev. 48, 125 (2003).

${ }^{35} \mathrm{X}$. Li and B. Bhushan, Mater. Charact. 48, 11 (2002).

${ }^{36}$ J. J. Cuomo, J. P. Doyle, J. Bruley, and J. C. Liu, Appl. Phys. Lett. 58, 466 (1991).

${ }^{37}$ A. C. Ferrari and J. Robertson, Phys. Rev. B 61, 14095 (2000).

${ }^{38}$ P. Lespade, R. Aljishi, and M. S. Dresselhaus, Carbon 20, 427 (1982).

${ }^{39}$ F. C. Marques, R. G. Lacerda, A. Champi, V. Stolojan, D. C. Cox, and S. R. P. Silva, Appl. Phys. Lett. 83, 3099 (2003).

${ }^{40}$ R. Kleber, W. Dworschak, J. Gerber, A. Fuchs, T. Putz, J. Scherer, K. Jung, and H. Ehrhardt, Vacuum 41, 1378 (1990).

${ }^{41}$ M. A. Tamor and W. C. Vassell, J. Appl. Phys. 76, 3823 (1994).

${ }^{42}$ J. Tersoff, Phys. Rev. B 44, 12039 (1991).

${ }^{43}$ F. Szuecs, M. Werner, R. S. Sussmann, C. S. J. Pickles, and H. J. Fecht, J. Appl. Phys. 86, 6010 (1999).

44J. Robertson, Phys. Rev. Lett. 68, 220 (1992).

${ }^{45}$ B. Bhushan, Diamond Relat. Mater. 8, 1985 (1999).

${ }^{46}$ E. Zussman, X. Chen, W. Ding, L. Calabri, D. A. Dikin, J. P. Quintana, and R. S. Ruoff, Carbon (in press). 